\title{
Memórias do Cativeiro e Transição
}

\author{
Agostinho Maria Dala Vecchia
}

O objetivo do nosso trabalho é recuperar a memória da escravidão através de depoimentos orais de filhos e netos de escravos e traçar as linhas mestras da história do negro na Zona Sul do nosso estado. Apresentaremos também alguns aspectos da sua situação atual. A principal documentação utilizada é o conjunto de depoimentos orais que serão colhidos junto a trinta pessoas descendentes de escravos. Parte destas entrevistas já foi transcrita. Realizamos esta presente comunicação especialmente a partir das dez primeiras.

Os entrevistados situam-se na faixa de 65 a 100 anos de idade. Os depoentes foram questionados a respeito de seis dimensões da vida social, a saber: a dimensão econômica, a política, a educativa, a familiar, a recreativa e a religiosa. Sobre estes aspectos, procuramos resgatar a memória da escravidão e a história do negro da nossa Região nos últimos 100 anos. Com o esquema adotado, procuramos levar em consideração os âmbitos fundamentais da relação do homem como outro, com a natureza e com a divindade. No processo vivo, essas relações se institucionalizam formando a cultura.

Não discutiremos agora se a institucionalização da vida social tem ou não seu principal mediador no modo de produção. Adotamos este esquema para que permitisse colher um volume maior, mais rico e mais denso de dados para ser analisado. As fontes orais serão confrontadas com outras fontes documentais e com as análises do assunto mais elaboradas e teorizadas. Contudo, a nossa comunicação está baseada exclusivamente nas fontes orais. 
A idéia de um trabalho mais amplo surgiu durante o altimo seminário de História Sócio-Econômica do Brasil I, realizado em julho de 1990, no Curso de Mestrado em História da PUCRS. A sugestão do trabalho foi dada pelo professor Mário Maestri, após ouvir uma síntese da entrevista realizada com a primeira depoente: Celina Soares.

Após este estímulo inicial, a tarefa foi ganhando força, passo a passo. Cada depoimento uma revelação, uma surpresa, uma emoção. Eram a história de indivíduos e a de um povo revelando-se contundentes, vivas, empolgantes e trágicas.

A voz silenciada do negro da nossa Região é uma denúncia. O negro encontra-se lançado à marginalidade econômica, política e cultural ainda hoje. Pelotas é um exemplo de cidade que edificou seu explendor aristocrático sobre o trabalho escravo. E até hoje, estende um silêncio sepulcral sobre esta realidade de injustiça. Embora saibamos que ninguém é isento ideológica e políticamente, vamos procurar manter-nos estritos à linguagem "objetiva" e apresentar os traços comuns da escravidão. A maioria dos depoimentos citados acima foram prestados por pessoas que migraram do campo para a cidade e apresentam uma memória do escravismo rural.

\section{A produção às custas da vida}

A memória oral da escravidão revela que os escravos trabalhavam de 'sol-a-sol'. Esta foi uma expressäo usual dos depoentes. Percebe-se que os escravos trabalhavam no mínimo de 10 a 12 horas diárias. As interrupções para a alimentação eram rápidas e vigiadas. Eram executadas tarefas ordinárias de limpeza, cozinhar, arrumar a casa e lavar a roupa. $\mathrm{O}$ abastecimento de lenha, água e mantimentos para a cozinha somava-se a estas atividades.

Uma parcela dos escravos trabalhava nos jardins, hortas e pomares em torno da casa. Outros, cuidavam dos animais domésticos e da fabricação artesanal e semi-industrial de canjicas, farinha, tecidos e calçados de couro. O trabalho produtivo da roça ou do campo ganhava maior intensidade de acordo com as condições da propriedade e de sua localizaçảo. De modo geral, a produção pecuária foi predominante sobre a produção agrícola na Zona Sul. As fazendas que estavam situadas nas regiões da Serra do Tapes e com maior densidade de vegetação, davam prioridade à produção agrícola. A produção era diversificada e orientada 
para o comércio e para a subsistência. O principal contingente de escravos era empregado nestas atividades produtivas.

O desenvolvimento da pecuária foi incrementado com a implantação das indústrias do charque, desde o final do século XVIII. A natureza desta atividade pastoril não exigia mais do que a utilização de uma ou duas dezenas de escravos, mesmo na grande propriedade. As antigas sesmarias - também chamadas sucessões - foram lentamente divididas e subdivididas. Muitos caminhos pelos interiores dos municípios da região surgiram das trilhas das tropas de gado comercializadas nas charqueadas de Pelotas e outras cidades.

$\mathrm{O}$ trabalho escravo era cercado de violência e brutalidade. A sistemática vigilância e a repressão foram aspectos deste modo de produção. A generalizada agressão física é a face exterior da extrema violência com que era tratada a pessoa do escravo. $\mathrm{O}$ mito de que a escravidão no Rio Grande do Sul foi mais branda e suave foi um mecanismo ideológico para encobrir uma situação marcada por atitudes que reclamam justiça. Os depoimentos dos nossos entrevistados desmascaram com facilidade tais afirmações.

É flagrante a contradição daqueles que afirmam que houve senhores bons com seus escravos. A escravidão por si já envolve uma violência radical: a supressão da liberdade. A liberdade é real à medida que há condiçōes objetivas de justiça econômica, de participação política e uma criativa articulação cultural. Mesmo abandonado os maus tratos físicos, o escravo era cooptado de diversas maneiras e mantido em estado de alienação.

A totalidade dos entrevistados referiu-se ao 'tronco' ao comentar o tratamento dos senhores com seus escravos. $O$ tronco era um pau fincado no chão no qual eram amarrados os escravos. Por influência da linguagem usual no Sul do Brasil, o tronco foi também denominado de palanque. Segundo o Novo Dicionário Aurélio "[...] do Rio Grande do Sul a São Paulo, o palanque é um tronco ou esteio grosso e forte que se finca no chão e ao qual se prende o cavalo para o domar, [...]." Alguns depoentes revelaram que, às vezes, os escravos eram amarrados a uma árvore ou a algum esteio de 'galpão' para serem castigados. Os açoites eram quase sempre executados pelo vigilante, raramente chamado feitor. De modo geral, o feitor é denominado 'carrasco'. As atitudes de rebeldia, indolência ou fuga eram 'corrigidas' no tronco. Porém, o capricho e o humor 
de senhor ou senhora de escravos era determinante para surrar os escravos.

Muitas vezes o escravo morria amarrado no tronco ou em decorrência dos maus tratos ali recebidos. São vários os depoimentos que se referem ao assunto. Um deles é ilustrativo:

"A - Pro tronco? O que era o tronco?

E - O tronco era um pau que eles botavam a pessoa assim pendurada, amarrada. A pessoas fica ali. $\mathrm{O}$ pau comendo pelas costas por onde cai. É uma judiaria.

A - Não machucavam os escravos?

E - Mas!!...se não machucavam?? Tinha que deixá.

Tinha muitos que saiam dali, iam pro chão pra morrê."’2

Às vezes eram mutilados membros dos escravos.

"LD - [...] Era só pra roça, pro trabalho.

E - E ainda apanhavam?

LD - Apanhava. Chegavam a cortá a lingua do ... assim

ó [indicando a pele da parte inferior da língua], essa pelizinha pra ficá caido o beiço grande."3

O escravo era açoitado com um 'chicote'. Também era usada a chibata. Segundo o Novo Dicionário Aurélio, a chibata era um "junco ou vara delgada para fustigar." " $\mathrm{O}$ mesmo dicionário descreve a natureza e a utilidade do chicote. Distinto da chibata, é um "[...] cordel entrançado ou correia de couro ligada a um cabo de madeira e comumente usado para castigar animais." Os depoentes referem-se inclusive à 'suiteira', provavelmente um termo regional. Instrumento semelhante ao chicote com um entrançado mais fino e alongado, preso a um cabo de madeira. Outra forma atroz de tratamento dos escravos era o seu aprisionamento pelos pulsos e tornozelos em estacas de madeira e depois suspensos na posição horizontal. Não faltam crimes bárbaros como o que vai narrado aqui:

"LD - Era um patrão muito ruim. Desde os pais dele eram muito ruim. A mãe dele tinha até matado uma guria, uma empregadinha que ela tinha, com um ferro quente, 
não é. Espetou embaixo e ela morreu.

[...]

E - Ah, era 'filha de criação'.

LD - Era. Pretinha, né. Era pretinha. Enterrô no, debaxo do chiquero. [...]"

Ocorre também que geralmente não eram tomadas providências em relação a fatos como este. Variados depoimentos apontam a morte de escravos devida aos maus tratos.

Sendo muito breve o espaço para a nossa comunicação, vamos agora tratar da questão da alimentação. A maioria dos entrevistados refere-se à baixa qualidade dos alimentos dos escravos, inclusive quando era servida carne fervida ou assada. Os depoimentos citados abaixo dão idéia do tipo e da qualidade da comida:

"A - Como é que comiam os escravos?

M - Ah, comiam quarquer comida. Não comiam bem, não."7

"A - Que tipo de comida eles ganhavam?

E - Comida braba. Aquela farinha engrossada. Comida boa eles não davam." 8

"LD - [...] o nego não sabia comê carne.

$\mathrm{E}$ - O que eles comiam?

LC - Feijão.

E - E quê?

LD - Feijão, trigo, noé. Farinha de milho [...] E aquele farelo grosso que sai da farinha não é, aquele que era pro pão pra eles." $"$

"LD - Lá as mãe [...]. Mamadera não tinha, era guampa...

E - Tomava leite na guampa?

LD - É, faziam ..., cerravam a guampa daquele lado fino, botavam um torno ali embaixo e em cima botavam, botava um bico, embaixo botava um torno pra apertá, pra segurá o leite noé. Em cima botavam a ponta da guampa pra chuparem, corrê o leite."10

"F - [...] Mandavam a carne lá pro sinhor lá dentro e 
aquelas mais carne, assim, mais inferior, era para os empregados. Lá eles fazia as comida deles. Era abóbra, era isso, era aquilo. Tudo da fazenda. Milho..."11

"A - Que diz que era uma judiaria com os escravos! A comida diz que era uma porcaria. Não davam comida boa pros escravos..."12

Estes e outros relatos estão de acordo com o que tradicionalmente foi afirmado sobre a alimentação dos escravos na historiografia brasileira. Era uma alimentação produzida em cozinhas separadas.

Quanto aos aspectos da reprodução da mão-de-obra, os depoimentos dão conta de que existia uma preocupação que ultrapassava a prática da compra e venda do escravo. Havia preocupação também com a qualidade da mão-de-obra que poderia ser reproduzida.

"J - [...] que aquela gente, posso le dizê que tinha criação de nego.

E - Tinha criação de nego, é?

$\mathrm{J}$ - Porque naquelas época, å época que vivi também. [...] E quanto vendia naquela época! [..]

E - Mas muitos dos que nasciam na fazenda eram vendidos, então?

J - Tudo vendido.

E - E eles não tinham lá, talvez, o preto e a preta que eram para reproduzir escravos?

$\mathrm{J}$ - Tinham, tinham que era pra reproduzí.

$\mathrm{E}-\mathrm{Ah}$, tinham, é?

J - Tinham, tinham ...e digo mais: era nego escoído!

E - Mais forte?

J - Mais forte... Tinha que sê nego igual a mim ó (e bate com a palma da mão na canela), só que tinha que sê preto.

E - Sim.

J - Era 'canela fininha'!

J - É, ... aquilo dava nego especiale, eh, eh, eh."13

Com um processo semelhante à reprodução de animais de qualidade, uma negra trabalhadeira e saudável era escolhida para reproduzir com um homem forte, trabalhador e 'bom'. São muitas as referências de 'canela fina' que eram considerados de melhor qualidade para a 
reprodução. O negro inclusive era emprestado ou alugado a outras fazendas para tal finalidade. Em outro depoimento, afirma-se que eram encerradas várias negras com o sujeito reprodutor. O mais usual para a reposição da mão-de-obra era a compra do escravo no mercado. Os senhores comercializavam entre si. Certamente foi a dificuldade de repor a mão-de-obra nas últimas décadas da escravidão que condicionou este tipo de mecanismo. Os depoimentos apontam a existência de comércio de escravos com outras Regiões do Brasil.

Entre os distintos aspectos da dimensão econômica que estamos tratando, incluímos a questão da habitação. Existem várias denominaçōes para os alojamentos dos escravos. O mais comum é a denominação de "senzala". Dois depoentes utilizam a palavra sanzala, que, segundo Mário Maestri, é a pronúncia original africana. Por influência da língua portuguesa tornou-se mais usual senzala. "Quartinhos", "galpão", "salão" e inclusive "mangueira" foram expressōes usadas pelos depoentes para referir-se ao local em que permaneciam os escravos, especialmente durante a noite.

"LD - Nesta... sala, no salão grande deles lá né. Como é que se chamava? ... Ah, como era o [nome] do quarto que eles dormia?...

E - Não era senzala?

LD - Senzala, é!

E - Era na senzala, então?

LD - Era na senzala! Chegava aquela hora, 6h... (sinal com o polegar e o indicador) passava a chave!"14

Outro exemplo ilustrativo é o seguinte:

"E - Onde eles dormiam? Onde eles ficavam para morar?

A - Assim! Eles durmiam na rua assim... nuns quartinho mal..., mal arrumado.

E - Uns quartinhos?

A - Era uma casa separada da casa do dono?

A - Ah, diz que era assim, arretirada da casa deles. Tinha aquela casa bonita deles noé e aí os escravos, já 
sabe. Era naqueles rancho mais inferior, caindo. Assim eu ouvi meu pai contá."15

Os depoimentos referem-se também às condições de alojamento e do descanso dos escravos. Geralmente utilizavam algum trapo, colchão de capim ou palha, feito com sacos de estopa. Alguns usavam peles de ovelha. Quando a senzala era um grande salão, os escravos mantinham um fogo aceso à noite para o aquecimento do ambiente. Os escravos eram separados por sexo em repartições distintas. Em relação ao vestuário dos escravos, os depoimentos se referem a um vestuário mínimo de confecção rudimentar e com tecidos de sacos de algodão já usados. Estampados ou tingidos, variavam de acordo com o costume da casa. Há referência ao uso de peles bovinas e ovinas para o vestuário. Teríamos variadas citações a respeito do assunto.

\section{Quem decide faz política*}

A questão política é a segunda dimensão social que procuramos abordar. Seria estranho à natureza de um modo de produção escravista que houvesse qualquer participação decisória do escravo em relação à produção, à vida política e cultural. Nesta esfera de decisões, o escravo era excluído. Nós não tínhamos pergunta a fazer e os entrevistados naturalmente silenciaram. É um silêncio eloqüente enquanto é resultado da exclusão. Contudo, considerando a decisão no seu sentido mais amplo, vamos perceber que o senhor não conseguia apropriar-se da totalidade da vida e da liberdade do escravo. Os limites da totalidade eram muitas vezes ultrapassados pela decisão pessoal e por certas atitudes do sujeito.

Diante das circunstâncias às quais era submetido, o escravo encontrava um âmbito de decisão onde ele exercia sua resistência. Enquanto um homem consegue tomar uma decisão e uma atitude em relação à sua sorte e à de seus companheiros, está articulando-se politicamente. Os escravos da Região forjaram as suas formas de resistência. Isto repercutiu na produção e na vida da 'casa grande'. Os seguintes depoimentos são ilustrativos:

\footnotetext{
* Política tem aqui o sentido amplo das relações que envolvem um ato de decisâo.
} 
"A - Me diz uma coisa: tinha algum escravo que se matava, assim, desacorçoado da vida?

E. Não, eles preferiam fugir.

[...], sim, porque se eles se matassem ali, eram capaz de picá eles mais, né. Então eles fugiam."16

"A - A senhora sabe de algum negro que tenha fugido e se escondido em algum mato por lá?

LD - Tinha muitos, noé! [...]

Às vezes chegavam tarde da noite, dispois... A minha mãe ajudô muito."17

Outras formas de resistência também são relatadas. O suicídio era uma das formas extremas utilizadas pelos escravos. A forma mais forte de procurar a superação da opressão sofrida. Este era um fenômeno comum no escravismo brasileiro. É a denúncia mais forte da brutalidade dos tratamentos neste sistema de temor e barbárie.

"E - Eles viviam muito tempo ou morriam de judiaria? L.D. Uns morriam de judiaria, né. Outros, mesmo se matavam por si porque não queriam vivê mais, não tinham vida para eles."18

Este outro depoimento aponta a resistência articulada pelos quilombolas:

"E - E conta uma coisa: e os escravos às vezes não se revoltavam?

F - Ah, muitos fugiro pra esses tal de ... como é que chamam? Como é aquele lugar que (se) os escravo fugisse, se habita e depois o senho tinha... não mandava ninguém lá porque morriam.

[...]

Não, os quilombo!

[...]

Era o nome do lugar, do mato que eles se metia. $\mathrm{O}$ quilombo acho que era o nome daquele lugar! Se metiam lá, fugiam, escrava e tudo. E lá eles faziam a função deles lá. Lá deviam fazê as casa deles por lá. Mas acontece que 
os que tavam fugido, os de lá da fazenda, enquanto procuravam, mas... morriam tudo. E muitos iam, até escapavam à noite, iam lá dizê: óia, cuidado queo sinhô está espalhando tribos e tribo de gente pra descobrir vocêis! Vocês se cuidem. E eles, ou iam pra outro ou ficavam no mesmo lugar esperando: 'aquele que entrá aqui eu mato!' E a boca da entrada... era uma toca: 'Não tem nada, o que aponta aí, stão tudo morto'. Assim... era assim. E, outros, às veis, iam ispioná. Em parte de chegá diziam assim: 'Ah, não... e etal'. Dipois iam imbora e diziam pro sinhô: 'Olha, estão assim, assim, armados' E - Então tinha gente que traia os outros companheros?

F - Aí sim. Tinha... ah, os próprios escravos, uns eram bom pros otro e quando davam de querê puxá o saco do sinhô! Lá dentro... não ganhavam nada, que eles apanhavam iguar. Mas, só pra fazê marvadeza. Não sei se eles se sentiam mal pra alguma coisa, e... matavam."19

Maria Filomena refere-se também ao suicídio por incineração, enforcamento. Narra inclusive um caso de resistência onde um escravo, através de um processo de domínio mental e físico, projetava a dor da pancadaria sobre o corpo do 'sinhô' ou da 'sinhá' que acabava morrendo. Este caso pode ser considerado anedótico, mítico ou um ato de bruxaria.

Certamente os escravos a consideravam decorrente de uma força mitológica ou da própria capacidade do bruxo.

A resistência era motivada também pela sabedoria humana amadurecida no sofrimento. Muitos escravos preferiram submeter-se conscientemente às exigências do trabalho intensivo. Assim evitavam maiores dores e conseguiam sobreviver. A indolência pareceria a forma mais comum de resistência à produção. A Historiografia é clara em mostrar que esta atitude afetou toda a produção colonial brasileira. A freqüência dos castigos e a permanente vigilância, são prova de que o problema não foi satisfatoriamente resolvido.

\section{O saber é instrumento do poder}

Estas e outras formas de resistência podem ser consideradas atitudes políticas. A própria natureza e as exigências do modo de produção escravista não teriam razão e espaço para permitir um processo 
de educação formal para o escravo. O máximo de tempo diário era empregado nos trabalhos da casa ou da produção. A má alimentação, a debilidade e o cansaço seriam também fatores determinantes. Por intuição ou não, o proprietário percebia a inconveniência de instruir escravos uma vez que ele próprio, às vezes, possuía pouco ou nenhum nível de instrução.

A produção era realizada sem maiores exigências técnicas. Os trabalhos, quase sempre rudimentares e artesanais, comportavam apenas um aprendizado empírico. $\mathrm{O}$ acesso à escola era difícil aos próprios filhos dos senhores. Alguma instrução era recebida em casa. Professores particulares passavam temporadas na fazenda com essa finalidade. Não existiam escolas nas zonas rurais e o transporte para a cidade ou para as capitais só era possível a uma minoria. $\mathrm{O}$ saber era detido por aqueles que possuíam o poder econômico e político.

Porém, na cidade havia excessões que ganhavam destaque. É o caso de Maria Salomé da Silva Santos, narrado por seu sobrinho-neto, José Facundo Mira:

"JM - [...] A roupa de Nossa Senhora do Rosário foi bordada pela mia tia Salomé da Silva Santos. A t' Salomé nasceu em Pelotas no ano de 1873, [...] Uma nega diferente para a época pois aprendeu a ler, a escrever, entendia de música e tocava piano."20

\section{Toda gravidez será castigada}

Estamos nos referindo à instituição social da família. É a quarta dimensão social que procuramos abordar com nossos questionamentos. A gravidez da escrava geralmente era encarada como prejuízo das atividades produtivas. A tendência era castigar a escrava porque não era permitida a convivência sexual. Esta acabava ocorrendo fortuitmente.

"E - E eles tinham filho. Nem podiam. Deus o livre. Se eles notasse que uns escravo tavum namorando. Nem pudiam. Deus te livre!

A - E se a escrava ficasse grávida? 

E - Ah, ficava um escravinho. Mas já tinha que se criá naquele leme, ali, conforme os otro."21

O namoro conseqüentemente era algo proibido:

"E - $[\ldots]$ Cada mulato! Tinha uns que namoravam
escondido."

A gravidez causava transtornos:

LD - $O$ senhor sabe, trabalha um dia bem, outro dia mal, noé. E aí eles vivero. Principalmente, se elas ganhavam filho...! ih! Se arvorotavam com aquelas nega que ganhavam filho. Eles passavam trabáio."23

O depoimento abaixo revela que não havia a instituição da família. Escravo e escrava se amigavam. E diante do fato de que os escravos morriam devido às condições de trabalho e ou eram mortos. A gravidez era aceita como forma de reprodução da mão-de-obra:

"E - E o senhor não ficva bravo quando as negras ficavam grávidas e ganhavam nenen?

F - Às veis eles ficavam brabo, otas veis eles queriam porque iam morrê e eles matavam. Que aquela gente do tempo antigo era uma gente muito bruta, não sabiam nem lê. A mãe disse que tinha muitos que não sabiam lê. [...]"24

Maria Filomena aponta ainda para o fato de que as vinculações, da família proprietária com os escravos, traziam transtornos e constrangimentos. O recém-nascido era dado ou morto. As relações sexuais e o parto eram vistos como algo animalesco.

"E - E como é que o escravo, a escrava... se juntavam? casavam? como é que tinham filhos? 
A - Ora, agora aí o senhor me aperta. Eu nunca vi. Eu acho que argum nem casavam noé. Vinham assim como bicho. [... $]^{\prime 25}$

O relato de João Rodrigues, demonstra o modo como eram encaradas as relações sexuais dos escravos:

"J - [...] É ela contava o período que ela com ... procurô construi família. Ela contava que teve encerrada num quarto e um véio, conheci muito o véio., me lembro muito dele, ... ficava na otra peça. Então ela contava, as trapaça que eles fizer pra se encontrá, os nego véio. Véio ... novo naquelas época deles. Então, por ali ... começô aquela construção que incrusive eu sou daquela, né ...

E -Eles conseguiram casa, então? Não era assim! Então?

J - Não era bem assim! Lá foro... lá tinha aquela conversa, tal e coisa... até que descobriro!! ... Bah!! ... meu sinhô, mia iaiá, íh! meu sinhô, foi aquela surra!!

E - Não podiam namorar, então?

J - Não, o véio tava robando! Tar Tobia, um home grande!...

E - Uhm, muito alto?

J - É, forte e ela era uma cabrochinha, bachota e gorda. Usava aquele vestido, parecia beduina, grande...! Mia bisavó Ingérica (Angélica) [...] $]^{26}$

Escravo não brinca, trabalha

Originariamente recreação tem o sentido de recriar as relações fundamentais dos homens em sociedade. Recriação seria o ato pelo qual o homem se rearticularia como homem. Para a sociedade capitalista, a recreação tem o sentido de reproduzir as relações competitivas e individualistas. Na sociedade escravista, não há espaço para a recreação porque o domínio é constante e originário, a vigilância é permanente e o trabalho devora as energias. $\mathrm{O}$ conjunto de relatos abaixo mostra que $\mathrm{o}$ escravo não pode sair, divertir-se. Se havia alguma dança, ela se realizava na senzala. 
"A - Eles podiam sair para se divertir?

E. Diversão não tinha nada. Diversão era o laço, e só!’’27

"LD - [...] E ali o escravo não saia para lado nenhum. Era só pra roça, pro trabáio."2s

"E - E os velhinhos?

LD - Não podiam ter um divertimento, não podia tê nada. Era a vida de um bicho. [...] Faziam festa pra eles lá na senzala.

E - O que eles ganhavam no dia da festa?

LD - Só ropa, ropa. Os calçado. Eles ganhavam as coisa pra festa." 29

Para quem trabalha forçado e tem sua vida cerceada em quase todas as suas dimensões, teria sentido a recreação? Festa seria para festeja o quê? Se a festa é celebração, há motivo para celebrar alguma coisa na vida de escravo?

A religião da justiça ou da alienação.

Além da família e da recreação, a religião é um dos âmbitos da vida e das relações. Distinta historiografias e interpretações da sociedade atribuíram um sentido preponderante e até determinístico à economia ou à política. Deixou-se de tratar a religião como uma instituição cultural importante, atribuindo-lhe uma mera fachada ideológica. Nós consideramos importante questionar o entrevistado na perspectiva religiosa. O depoimento de Maria Filomena, além de caracterizar a religião dos escravos, aponta a exigência de uma religião com sentido social e de justiça. A contradição dos senhores cristãos com os seus escravos, encontra-se logo na entrada da porta.

O sentido de resistência era buscado nas práticas de bruxaria e outras práticas de sentido religioso. Albertina Bandeira refere-se a feitiçarias e batuques. Uma situação bastante peculiares a muitos proprietários que eram ateus e não permitiam a prática religiosa.

"E - E esses escravos rezavam? Os patrões rezavam? Faziam eles rezá? 
LD - Não, não. Mas eles rezavam.

[...]

E - E eles conheciam padre?

LD - Conhecia, conhecia. Chegava a fugi os padre pra levá a comunhão.

$\mathrm{E}$ - Ah, tinha que ser escondido?

LD - Escodido. se soubessem se viravam contra os padre." 30

"E - Esses patrões tinham religião?

LD - Uns tinham, outros não tinham. uns gostavam de religião, outros não gostavam. A religião era muito poca, tudo. Depois é que foi crescende ... a religião." 31

E por último e mais uma vez, um depoente introduz um julgamento ético à religião praticada pelos senhores. O lugar de destaque dos oratórios na casa não tinha o mesmo significado na relação do 'sinhô' com seus escravos. Fica assinalada a impotência transformadora de uma religião usada ideologicamente para a manutenção do status quo.

"F - Ah eram uns demônio e tinham mania de artar com imagem dentro de casa! Entrava numa casa dessa, do sinhô ruim mesmo, a premera peça que tu entrava era na igreja.

A - Ah, uma igreja? Uma capela?

F - Uma capela mesmo, dentro de casa, cheia de santo: Jesus e varias image muito bonita, tudo arrumado, tudo envernizado, cheio de artarzinhos pra se ajoeiá. Mas eram ruim. [...]

Diz que iam à missa, rezavam, oravam em casa, [...] Tava tirando um pouco dos pecado, mas que na hora do morrê, não adiantava (risadas). É isso aí!"32

O tempo para esta comunicação já está esgotado. Nós temos a exposição sobre a trajetória do negro no processo de inserção no trabalho e na sociedade, após a escravatura. Este caminho para o negro na Zona Sul, foi lento e difícil. Um século marcado pela marginalização. A periferia das cidades regionais, especialmente Pelotas, assinala a presença de maioria negra. A maioria dos nossos entrevistados mora nas casas mais pobres, quando não em casebres, da nossa periferia urbana. 


\section{Notas}

1. FERREIRA, Aurélio Buarque de Holanda. Novo Dicionário Aurélio da Língua Portuguesa. 2.ed. rev. ampl. Rio de Janeiro, Nova Fronteira, 1986. p.1248.

2. Depoimentos de Albertina Bandeira. p.25.

3. Depoimentos de Luiza Dorneles. p.44.

4. FERREIRA, Aurélio Buarque de Holanda. Novo Dicionário Aurélio da Língua Portuguesa. 2.ed. rev. ampl. Rio de Janeiro, Nova Fronteira, 1986. p.395.

5. Cf. p.395.

6. Depoimentos de Luiz Dornelles. p.52.

7. Depoimentos de Manoel Fernandes. p.126.

8. Depoimentos de Luiza Dornelles. p.44.

9. Depoimentos de Luiza Dornelles. p.52.

10. Depoimentos de Luiza Dornelles. p.52.

11. Depoimentos de Maria Filomena. p.64.

12. Depoimentos de Antonia Fagundes. p.79. (Antonia Fagundes é chamada também Antoninha na nossa entrevista.)

13. Depoimentos de João Rodrigues. p.95.

14. Depoimentos de Luiza Dornelles. p.44.

15. Depoimentos de Antonia Fagundes. p.79.

16. Depoimentos de Antonio Fagundes. p.79.

17. Depoimentos de Luiza Dornelles. p.56-7.

18. Depoimentos de Luiza Dornelles. p.44.

19. Depoimentos de Maria Filomena. p.68.

20. Depoimentos de José Facundo Mira. p.98.

21. Depoimentos de Albertina Bandeira. p.27.

22. Depoimentos de Albertina Bandeira. p.27.

23. Depoimentos de Luiza Dornelles. p.44.

24. Depoimentos de Maria Filomena. p.67.

25. Depoimentos de Antonia Fagundes. p.80.

26. Depoimentos de João Rodrigues. p.83-4.

27. Depoimentos de Albertina Bandeira. p.25.

28. Depoimentos de Luiza Dornelles. p.44.

29. Depoimentos de Luiza Dornelles. p.45.

30. Depoimentos de Luiza Dornelles. p.45.

31. Depoimentos de Luiza Dornelles. p.58.

32. Depoimentos de Maria Filomena. p.72. 